\section{OWE-17 NUTRITIONAL CARE PATHWAYS OF PATIENTS WITH MALIGNANT BOWEL OBSTRUCTION: PRELIMINARY FINDINGS FROM 8 UK CENTRES}

${ }^{1} \mathrm{PS}$ Patel ${ }^{*},{ }^{1} \mathrm{~K}$ Fragkos, ${ }^{1} \mathrm{~N}$ Keane, ${ }^{2} \mathrm{C}$ Mountford, ${ }^{2} \mathrm{D}$ Wilkinson, ${ }^{2} \mathrm{~A}$ Johnson, ${ }^{3} \mathrm{M}$ Naghibi, ${ }^{3} \mathrm{D}$ Chan, ${ }^{3} \mathrm{~B}$ Roberts, ${ }^{4} \mathrm{P}$ Neild, ${ }^{4} \mathrm{Y}$ Metin Devrim, ${ }^{5} \mathrm{P}$ Allan, ${ }^{5} \mathrm{M}$ Fitzpatrick, ${ }^{5} \mathrm{M}$ Gomez, ${ }^{6} \mathrm{~S}$ Williams, ${ }^{6} \mathrm{~K}$ Kok, ${ }^{7} \mathrm{~L}$ Sharkey, ${ }^{7} \mathrm{C}$ Swift, ${ }^{8} \mathrm{~A}$ Forbes, ${ }^{1} \mathrm{~S}$ Mehta, ${ }^{1} \mathrm{~F}$ Rahman, ${ }^{1} \mathrm{~S}$ Di Caro. ${ }^{1} \mathrm{Gl}$ Services, University College London Hospital, London, UK; ${ }^{2}$ Department of Gastroenterology, Newcastle upon Tyne Hospitals, Newcastle; ${ }^{3}$ Intestinal Failure Unit, St Mark's and Northwick park hospital, London; ${ }^{4}$ Department of Gastroenterology, St George's University Hospitals, London; ${ }^{5}$ Translational Gastroenterology Unit, Oxford University Hospitals, Oxford; ${ }^{6}$ Department of Gastroenterology, St Bart's Hospital, London; 'Intestinal Failure and transplant unit, Addenbrookes' hospital, Cambridge; ${ }^{8}$ Department of Gastroenterology, Norfolk and Norwich University Hospital, Norwich

\subsection{6/gutjnl-2019-BSGAbstracts.328}

Introduction Variation in access to parenteral nutrition (PN) in patients with malignant bowel obstruction (MBO) and intestinal failure exist due to differing practice, beliefs and resource access. We aimed to examine nutritional care pathways of MBO patients at $8 \mathrm{UK}$ Tertiary Centres.

Methods A retrospective cohort study of $\mathrm{MBO}$ adults admitted to hospitals between 1.1.1-1.12.16 and any readmissions up to 31.12.17. Demographic, nutritional and medical data were analysed by comparing patients referred (R) or not referred (NR) for PN. Differences between groups tested by KruskalWallis and Chi-Squared tests, survival by Kaplan Meier Curves and Cox regression.

Results 197 patients with 371 MBO admissions (median 66 yr, (range 3-7 yrs, 30\% male), with 2 admissions/patient (-) were identified. 56/197 patients were referred ( $\mathrm{R}$ group).
Gynaecological and gastrointestinal cancers predominated (72\%). $79 \%$ of patients had metastases. $66 \%$ of admissions presented with subacute BO, $60 \%$ with single-, $35 \%$ with multi-level BO in either complete $(45 \%)$ or partial BO $(55 \%)$.

Admission malnutrition screening, MDT PN discussion and dietetic contact were more likely to occur in the $\mathrm{R}$ group103/371 (R vs.NR group: $96 \%$ vs. $84 \%, \mathrm{P}<0.01 ; 54 \%$ vs. $1 \%, \mathrm{P}<0.0001 ; 27 \%$ vs $17 \%, \mathrm{P}<0.0001)$. Admission weight loss $5.9 \%$ (-45\% to $26.2 \%)$. No difference observed in weight or BMI at start of PN (R vs. NR: 56 vs. $58 \mathrm{~kg}$, BMI 21.2 vs. $21.7 \mathrm{~kg} / \mathrm{m}^{2}$ ) or weight at follow-up (-months) (R vs. NR 54 vs. $57 \mathrm{~kg}$ ). 44/103 R group admissions received inpatient PN only, with 47 patients discharged or already established on HPN. Survival was 158 days (13-71) with no difference between groups, Figure 1.

Conclusion All patients with $\mathrm{MBO}$ presented with cachexia. Less than half were referred to the Nutrition team. There were no differences in weight loss and survival at follow up. This may suggest that PN was effective, but further comparison of disease severity and other prognostic markers between the two groups would be necessary to determine this.

\section{OWE-19}

\subsection{6/gutjnl-2019-BSGAbstracts.329}

Licence to publish not granted by author

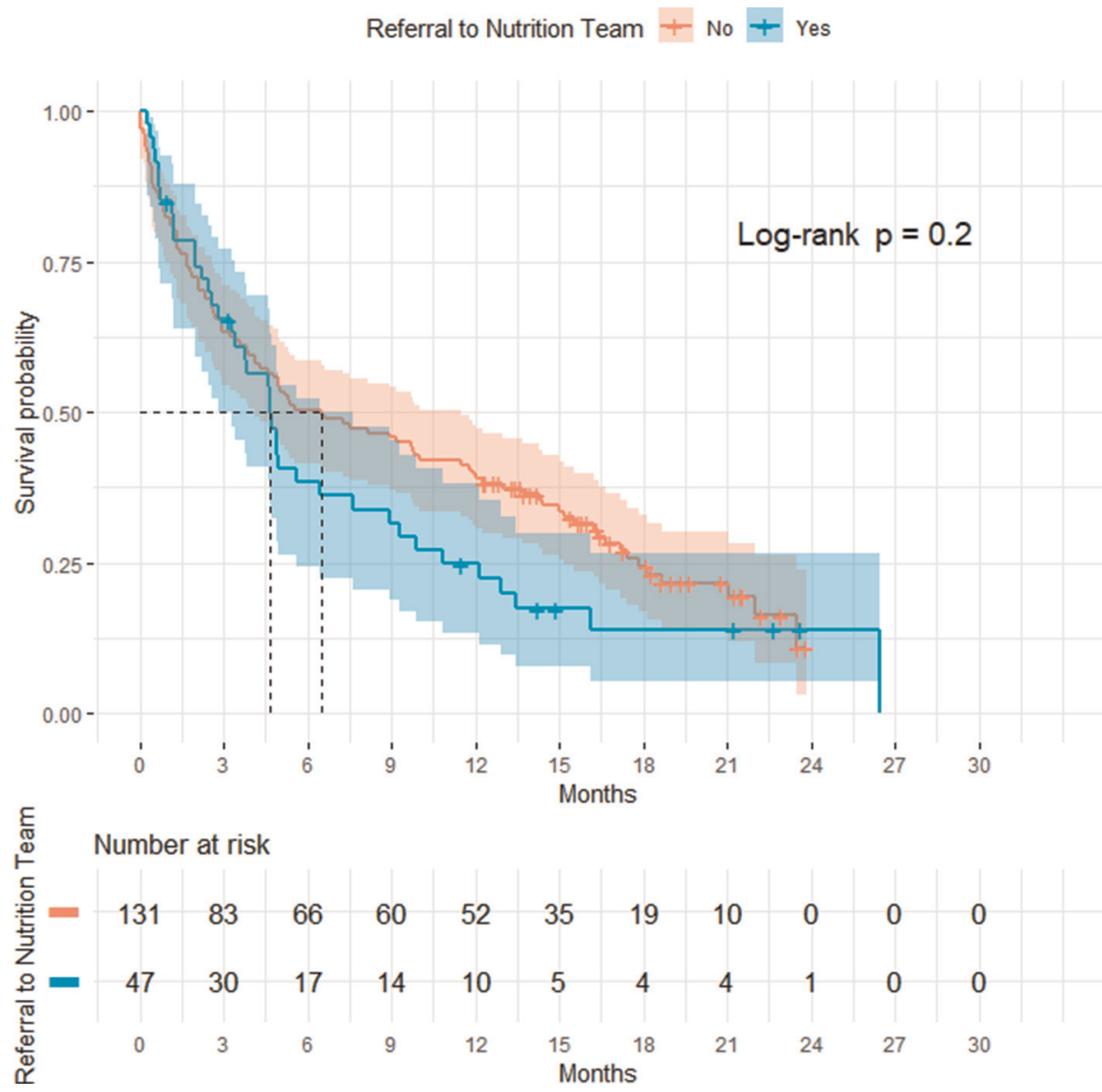

Abstract OWE-17 Figure 1 Survival by referral to nutrition team 